\title{
Adenocarcinoma arising in adenomyosis: report of an unusual case
}

\author{
Daniela COUTO ${ }^{1}$, Fernando MOtA ${ }^{1}$, TERESA SILVA ${ }^{2}$ AND \\ CARLOS DE OLIVEIRA ${ }^{1}$ \\ From the Departments of ${ }^{1}$ Gynecology, and ${ }^{2}$ Pathology, \\ University Hospital of Coimbra, Coimbra Codex, Portugal
}

Acta Obstet Gynecol Scand 2004; 83: 406-408. (C) Acta Obstet Gynecol Scand 832004

Keywords: adenomyosis, endometrial adenocarcinoma

Submitted 29 July, 2002

Accepted 21 October, 2002

Endometrial adenocarcinoma and adenomyosis are both common pathologic conditions that develop in the uterus.

Adenocarcinoma arising from adenomyosis is rare but has been described, with similar alterations in the endometrium. Furthermore, there have been a few reports of adenocarcinoma developing in adenomyotic areas without endometrial involvement (1-11).

We report a case of endometrial adenocarcinoma arising in a focus of adenomyosis localized in the outer half of the myometrium, with no involvement of the surface of the endometrium.

\section{Case report}

OFBGB, a 62-year-old, nulliparous, white woman, presented with postmenopausal bleeding for 2 years with no other complaints.

Menarche at the age of 11 years. Menopause at the age of 53 years. She had been on antidiabetic and antihypertensive drugs for several years. She was an obese woman with a body mass index of 34.2. Dilatation and curettage (D \& C) was performed, revealing endometrial hyperplasia with atypia. The serum level of CA-125 was within normal limits.

Magnetic resonance imaging of the pelvis showed four uterine nodules, with the biggest being $2 \mathrm{~cm}$ in diameter, hypodense at $\mathrm{TI}$ and $\mathrm{T} 2$, most probably corresponding to fibroids. In the myometrium there was a nodule with an intermediate sign at $\mathrm{T} 1$ and $\mathrm{T} 2$ that pushed inwards the adjacent endometrium. Inside this nodule there were two punctate images with an identical sign to that of the endometrium. This nodule may represent an area of adenomyosis (Fig. 1). The nodule was well circumscribed and localized in the inner third of the myometrium. The endometrium had normal thickness throughout the cavity. The cervix was normal. Abnormal lymph nodes were not identified.

\section{Abbreviations:}

D \& C: dilatation and curettage; FIGO: International Federation of Gynecology and Obstetrics; ER: estrogen receptor; PR: progesterone receptor.
The patient underwent a total abdominal hysterectomy with bilateral adnexectomy.

\section{Pathologic findings}

Gross examination of the surgical specimen, showed a uterus $(6.5 \times 4.0 \times 3.5 \mathrm{~cm})$ covered by smooth, glistening mucosa. The endometrial cavity $(4.5 \mathrm{~cm}$ in length) was a tiny slit with a tan-pink flat endometrium lining $(0.2 \mathrm{~cm}$ in thickness on average).

The myometrium measured $2.0 \mathrm{~cm}$ in maximum thickness and contained several cystic hemorrhagic areas (adenomyosis) in the whole thickness, as well as several nodules that had a white-tan whorled appearance and no hemorrhage or necrosis, except for nodule $(1.3 \mathrm{~cm}$ in its greatest dimension), subserosal, located on the lateral wall, near the fundus. It had a granular white appearance and was $0.7 \mathrm{~cm}$ away from the endometrial cavity.

\section{Histologic findings}

The normally situated endometrium was atrophic, without hyperplasia or malignant lesions (Fig. 2). There were several leiomyomas, as well as numerous adenomyotic foci in the whole thickness of the myometrium. The granular intramural nodule was a well-differentiated endometrioid adenocarcinoma, arising in adenomyosis (Fig. 3), and transition from adenomyotic epithelium to adenocarcinoma was observed in several foci. There was no involvement of the uterine serosa, but there was minimal myometrial (outer half) invasion (Fig. 4) and lymphatic involvement.

\section{Adjuvant therapy}

Postoperative radiation was offered to the patient. She was well 6 months after surgery, is regularly followed up and, so far, has no signs or symptoms of tumor recurrence.

\section{Discussion}

Adenocarcinoma arising in adenomyosis of the uterus is uncommon. However, malignant transformation of the glandular epithelium in adenomyotic foci is possible, as these foci are downward extensions of the basal layer of the endometrium, which has considerable growth potential (11). Thus, when persistent estrogenic stimulation is present, proliferative changes may occur in these foci, including hyperplasic changes that can develop into carcinoma.

There are a few documented cases of carcinoma arising in adenomyosis with or without endometrial involvement (1-10).

Rolly (1) published the first report in 1987. In 1980, a review of the literature carried out by Hernandez and Woodruff (5) revealed 16 cases of adenocarcinoma in adenomyosis. In eight of these cases the carcinoma was present only in adenomyotic foci; in the remaining eight cases there was malignant alteration in both surface and intramyometrial endometrium.

In 1986, Woodruff et al. (6) reported two more cases of adenocarcinoma arising in adenomyosis without surface endometrial changes. Both patients were postmenopausal women who underwent a total hysterectomy with bilateral adnexectomy because of persistent atypical cytologies, 

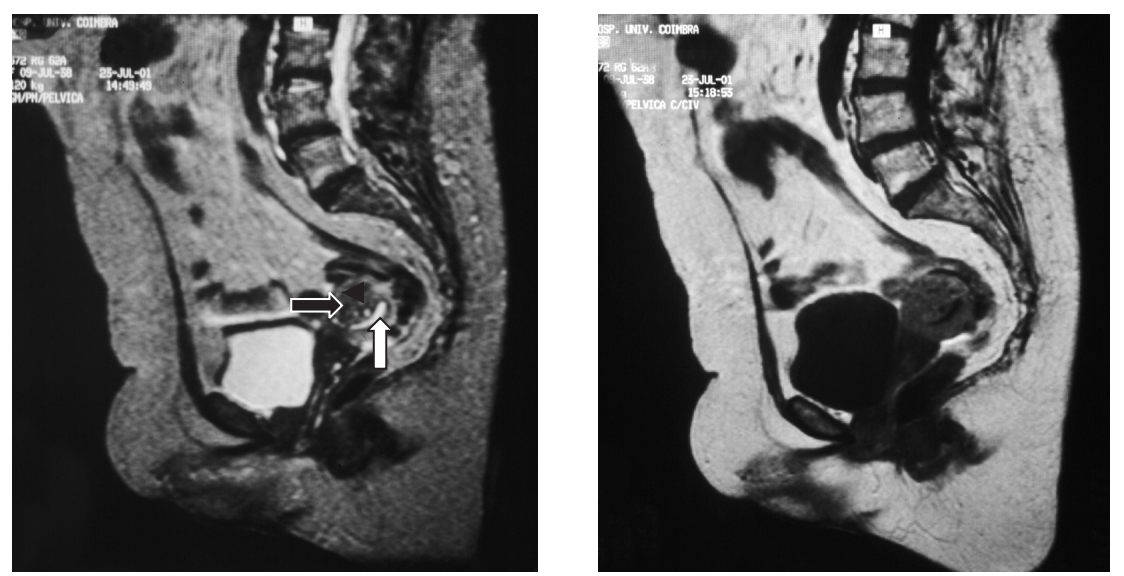

Fig. 1. Nodule in the myometrium with an intermediate sign at $\mathrm{T} 1$ and $\mathrm{T} 2$ that may represent an area of adenomyosis (black arrow), as there are two punctate images inside the nodule with an identical sign to that of the endometrium (white arrow).

despite negative findings on biopsies obtained by D \& C. In these cases, the diagnosis was only made after the histologic examination of the surgical specimens.

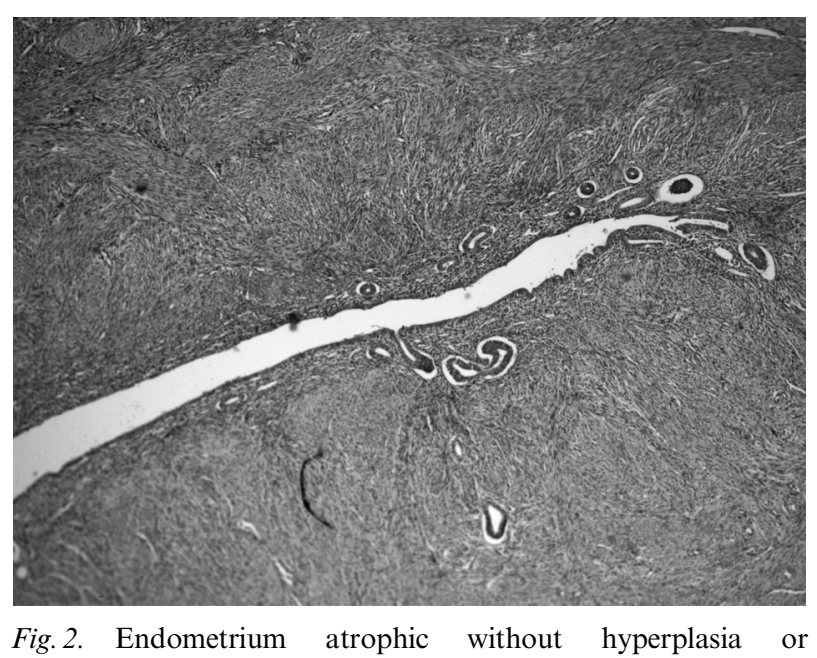
malignant lesions.

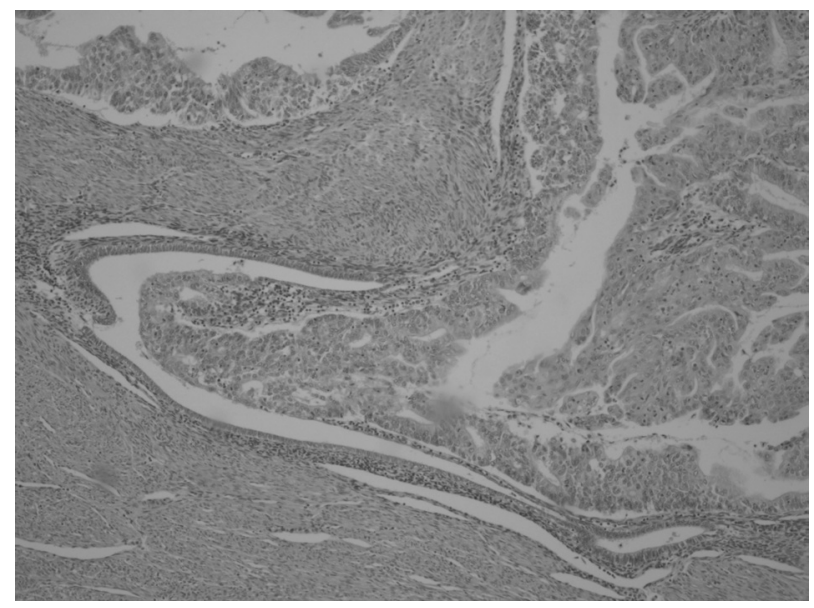

Fig. 3. Well-differentiated

endometrioid

adenocarcinoma arising in adenomyosis.
Finally, in 2001, Toshiki et al. (7) reported a similar case of adenocarcinoma arising in adenomyosis without endometrial involvement, but there were already lymph node metastasis and involvement of the uterine serosa by the time the diagnosis was made. Thus, based on the International Federation of Gynecology and Obstetrics (FIGO) classification system, the case was classified as FIGO stage IIIc. They made an immunohistochemical analysis of the growth factors, including estrogen receptor (ER), progesterone receptor (PR), p53, bcl-2 protein and Ki-67 antigen, and found no expression of ER, PR or bcl-2 in the carcinoma cells. However, there was focal expression of p53 and prominent expression of Ki-67. These results suggest that some biological factors, including oncogenes and tumor suppressor genes, may play a role in the carcinogenesis of endometrial carcinoma arising from adenomyosis without surface endometrial changes.

In our case, the adenocarcinoma arose from an adenomyotic foci situated in the outer half of the myometrium, there was no malignant transformation on the surface of the endometrium, but the tumor invaded the adjacent myometrium. We found it difficult to classify this tumor, as the FIGO classification system does not foresee these cases. However, because there were myometrial invasion (on the outer half) and lymphatic involvement, we classified and treated this tumor as FIGO stage Ic.

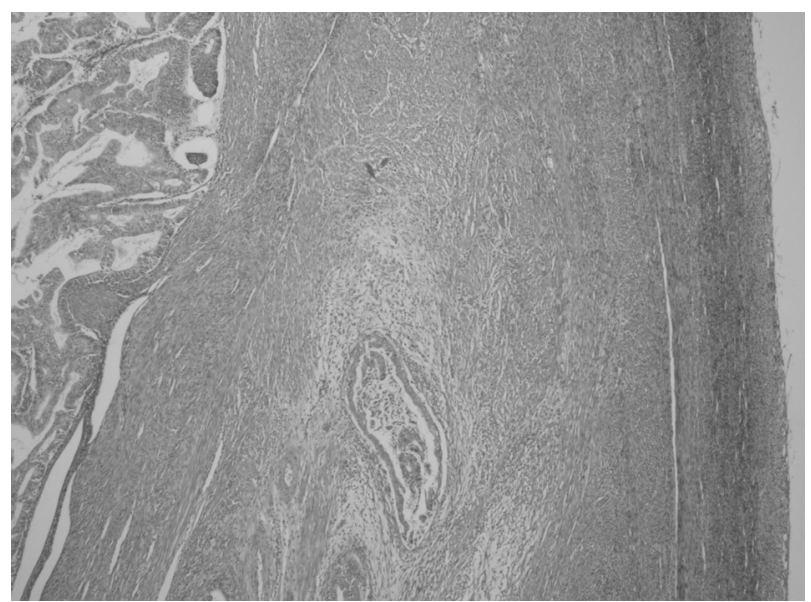

Fig. 4. Invasion of the myometrium without involvement of the uterine serosa. 
It is conceivable that in localized areas of adenomyosis, cellular changes occur, involving mutations of tumor suppressor genes and activation of oncogenes that may result in malignant transformation.

Additional cocarcinogenic factors, such as proliferative stimulation as a result of endogenous estrogens, may be responsible for further genomic instability that promotes development of cellular clones with invasive potential. In the present case, this hormonal stimulation might also have been operative, as it was diagnosed as an atypical hyperplasia, probably focal, which was completely removed by curettage.

Fortunately, adenocarcinomas arising in adenomyosis are rare events, because they generally represent pathologic findings of a surgical specimen.

Further efforts should be made to clarify the pathogenesis of these tumors, namely the genetic abnormalities encountered in neoplastic areas in comparison with the nontumor components of the adenomyotic focus.

\section{References}

1. Rolly F. Uber einen fall vonadenomyoma uterine uberbang in Karzinom und metastasen bildung. Virchows Arch (Pathol Anat) 1897; 150: 555 .

2. Colman HI, Rosenthal HA. Carcinoma developing in areas of adenomyosis. Obstet Gynecol 1959; 14: 342-8.

3. Jacques S, Lawrence D. Endometrial adenocarcinoma with variable-level myometrial involvement limited to adenomyosis: a clinicopathologic study of 23 cases. Gynecol Oncol 1990; 37: 401-7.

4. Kuwashima Y, Uehara T, Kishi K, Tajima H, Shiromizu K, Matsuzawa $\mathrm{M}$ et al. Intramural adenocarcinoma of the uterus, arisen from adenomyosis uteri, showing unique histologic appearances: report of two cases. Eur J Gynaec Oncol 1994; 6: 418-23.

5. Saul Kay WJ, Frable Goplerud DR. Endometrial carcinoma arising in a large polypoid adenomyoma of the uterus. Int $\mathbf{J}$ Gynecol Pathol 1988; 7: 391-8.

6. Hernandez E, Woodruff JD. Endometrial adenocarcinoma arising in adenomyosis. Am J Obstet Gynecol 1980; 138: 827-32.

7. Woodruff JD, Erozan YS, Genadry R. Adenocarcinoma arising in adenomyosis detected by atypical cytology. Obstet Gynecol 1986; 67: 145-8.

8. Toshiki Sasaky et al. Endometrioid adenocarcinoma arising from adenomyosis: report and immunohistochemical analysis of an unusual case. Pathol Int 2001; 51: 308-13.

9. Grayzel D. Carcinoma arising in an adenomyoma of the uterus. Am J Obstet Gynecol 1959; 14: 342.

10. Andrews HR. Case of carcinoma of uterus arising in adenomyoma. Proc R Soc Lond (Biol) 1921; 14: 321

11. Longacre T, Hendrickson M. Diffusely infiltrative endometrial adenocarcinoma: an adenoma malignum pattern of myoinvasion. Am J Surg Pathol 1999; 23: 69-78.

12. Siegler A, Camilien L. Adenomyosis. J Reprod Med 1994; 39: $841-53$.

Address for correspondence:

Daniela Couto, MD

Serviço de Ginecologia

Hospitais da Universidade de Coimbra

Praceta Prof. Mota Pinto

3049 Coimbra Codex

Portugal

e-mail: dcouto@net.sapo.pt

\section{Three-dimensional}

transvaginal sonographic diagnosis of asymptomatic interstitial pregnancy at 6 weeks of gestation

Chinnaiya Anandakumar and Nuruddin Badruddin Mohammed Antenatal Diagnostic Center, Division of Maternal and Fetal Medicine, Department of Obstetrics and Gynecology, National University of Singapore, Singapore

Acta Obstet Gynecol Scand 2004; 83: 408-410. (C) Acta Obstet Gynecol Scand 832004

Key words: 3D ultrasound scan; asymptomatic interstitial pregnancy; early diagnosis

Submitted 11 June, 2002

Accepted 17 January, 2003

Interstitial pregnancies account for $2-4 \%$ of all tubal pregnancies (1) and are especially feared because of their devastating outcome (2). Even with advances in transvaginal ultrasound technology, and although interstitial gestations can be identified at an early asymptomatic stage (2), it is still difficult to distinguish between an interstitial pregnancy and an angular pregnancy using two-dimensional (2D) transvaginal sonography (3). However, with the availability of $3 \mathrm{D}$ ultrasonography, diagnostic distinction between the various anatomic locations of tubal ectopic pregnancies is possible (4). This is of particular clinical importance as angular and interstitial pregnancies follow different clinical courses (5). Here, we report a case in which 3D transvaginal sonography with multiplanar analysis was used to confirm the diagnosis of asymptomatic interstitial pregnancy at 6 weeks of gestation.

\section{Case report}

A 32-year-old woman, gravida 5 para 0 , with a previous history of four recurrent first-trimester pregnancy losses, was referred to our antenatal diagnostic center at 6 weeks of amenorrhea for the evaluation and management of a leftsided tubal ectopic pregnancy. On presentation to us, the patient was asymptomatic. Her vital signs were stable and she had no pain or vaginal bleeding. Quantitative B-human chorionic gonadotropin (BhCG) concentration was $6671 \mathrm{IU} / \mathrm{L}$. Two-dimensional transvaginal ultrasonography was performed, revealing a $15 \mathrm{~mm} \times 13 \mathrm{~mm}$ gestational sac containing a viable embryo with crown rump length of $5 \mathrm{~mm}$ close to the left uterotubal junction. A corpus luteum was noted in the right ovary measuring $12 \mathrm{~mm} \times 11 \mathrm{~mm}$. Color flow Doppler ultrasound demonstrated a ring of fire sign, indicative of intense peritrophoblastic vascular activity surrounding the sac with resistance index of 0.64 . 
Copyright of Acta Obstetricia et Gynecologica Scandinavica is the property of Blackwell Publishing Limited and its content may not be copied or emailed to multiple sites or posted to a listserv without the copyright holder's express written permission. However, users may print, download, or email articles for individual use. 